https://helda.helsinki.fi

The use of knowledge in evidence-informed voluntary conservation of Finnish forests

\title{
Salomaa, Anna
}

2016-12

Salomaa , A , Paloniemi , R , Hujala , T, Rantala , S , Arponen , A \& Niemela , J 2016 , ' The use of knowledge in evidence-informed voluntary conservation of Finnish forests ', Forest Policy and Economics , vol. 73 , pp. 90-98 . https://doi.org/10.1016/j.forpol.2016.09.004

http://hdl.handle.net/10138/198034

https://doi.org/10.1016/j.forpol.2016.09.004

cc_by_nc_nd

acceptedVersion

Downloaded from Helda, University of Helsinki institutional repository.

This is an electronic reprint of the original article.

This reprint may differ from the original in pagination and typographic detail.

Please cite the original version. 
This is a pre-copy-editing, author-produced PDF of an article accepted following peer review for publication in Forest Policy and Economics.

The definitive publisher-authenticated version is available online, http://dx.doi.org/10.1016/j.forpol.2016.09.004

Creative Commons Attribution-NonCommercial-ShareAlike 2.5 License

\section{The use of knowledge in evidence-informed voluntary conservation of Finnish forests}

Anna Salomaa a, *, Riikka Paloniemi b, Teppo Hujala c, Salla Rantala b, Anni Arponen d, Jari Niemelä a

a Department of Environmental Sciences, P.O. Box 65, 00014, University of Helsinki, Finland

b Finnish Environment Institute, P.O. Box 140, 00260 Helsinki, Finland

c Natural Resources Institute Finland, Koetilantie 5, 00790 Helsinki, Finland

d Department of Biosciences, P.O. Box 65, 00014, University of Helsinki, Finland

*Corresponding author. E-mail addresses: anna.salomaa@ helsinki.fi (A. Salomaa),

Keywords: conservation politics, evidence-based policy, forest biodiversity, knowledge use, policy implementation, stakeholders

\section{Introduction}

There is a need to improve the use of scientific research on the biodiversity of forest ecosystems in policy formulation and practice. In conservation science, the limited practical influence of ecological evidence has been described as a research-implementation gap (Pullin and Knight 2003, Spilsbury and Nasi 2006, Sutherland et al. 2004, van Kerkhoff and Lebel 2006). Propositions for evidence-based actions highlight the importance of evaluating, and creating syntheses and recommendations based on existing scientific knowledge (Pullin and Knight 2003, Sutherland et al. 2004). However, the use of ecological knowledge and therefore the effectiveness of the policy instrument are not the only reasons why policies can be considered to have merit, worth, and value 
(Mickwitz 2003). For example, the Natura 2000 network, which has been planned according to the principle of ecological effectiveness, has been criticized because of its disregard to the expectations, needs, and cultural circumstances occurring in localities (Hiedanpää 2002). Different evaluation criteria for environmental policy instruments can be used to understand and evaluate the various achievements of a policy; Mickwitz (2003) proposes to focus on relevance, impact, effectiveness, persistence, flexibility, predictability, legitimacy, transparency, and equity. The quest to understand such numerous aspects calls for using different types of knowledge in addition to ecological knowledge. In other words, evidence-based conservation should adopt a wider understanding of evidence and aim at understanding the complexity of evidence use in the policy process, and should thus be called evidence-informed conservation (Adams and Sandbrook 2013).

The idealistic view sees scientific information trickling down to the policy, but translating science into policies and implementation is actually a complex process compromising between the authority of science and other interests (van Kerkhoff and Lebel 2006). Relationships between science, policy, and practise have been studied, e.g. from the perspective of the science-policy interface, boundary organizations, forest policy preparation, communication, policy change, and knowledge mobilization (e.g. Böcher and Krott 2014, Cook et al. 2013, Ellefson 2000, Janse 2008; 2006, Klenk and Wyatt 2015, Sarkki et al. 2014, Spilsbury and Nasi 2006, van Kerkhoff and Lebel 2006). The linkage between science and implementation has been described to be emerging through participation, integration, co-production, learning, and negotiation (Böcher 2016, Böcher and Krott 2014, van Kerkhoff and Lebel 2006). Despite a growing interest to study evidence use in policy sectors ranging from health to conservation, little understanding exists on how evidence is used in implementation of forest policy in practise (Ellefson 2000, Klenk and Wyatt 2015, Oliver et al. 2014, Spilsbury and Nasi 2006); this is an especially relevant aspect in voluntary conservation, which is characterized by complexity and uncertainties encountered from numerous involved actors and their decisions. 
Voluntary policy instruments have become more common in the arena of environmental policy and forest conservation (for example payments for ecosystem services, REDD), partly because of the dissatisfaction in regulation and its incapability to maintain biodiversity (Doremus 2003, Jordan et al. 2003, Primmer et al. 2014). What distinguishes voluntary conservation processes from nonvoluntary ones is the role of the individuals making decisions regarding participation. This aspect of individual-level decision-making is not evident in the general models of policy process e.g. consideration, decision, implementation, and evaluation (Jenkins 1978 p. 17); setting policy agenda, formulating policy responses, selecting and legitimizing policies, implementation, and policy evaluation (Ellefson 2000). In this paper we examine knowledge use during the implementation of voluntary forest conservation in Finland, where voluntariness is emphasized in the Forest Biodiversity Programme METSO (Government of Finland 2014, 2008). We use the Programme as a case to study science implementation in practise. The effectiveness of biodiversity conservation efforts in Finland is strongly related to forests, as they cover $75 \%$ of the land area.

In addition to landowners, who are key actors in policy implementation, various other stakeholders such as forest advisers and environmental officers, influence the success of voluntary conservation. Stakeholder participation is understood to increase the shared understanding of complex problems (Funtowicz and Ravetz 1993). Following this principle, voluntary conservation is thought to increase conservation acceptance by involving diverse actors in knowledge co-production and policy implementation processes. Participatory decision-making should increase legitimacy and produce better-informed decisions, but participation simultaneously challenges the dominance of natural sciences knowledge (Appelstrand 2002, van Kerkhoff and Lebel 2006). Understanding knowledge use in voluntary conservation therefore requires paying more attention to the variety of knowledges than when using control and command instruments.

In addition to scientific understanding in different disciplines, other knowledge types also exist. A person's local and practical knowledge can amalgamate with scientific knowledge (Fortmann and 
Ballard 2011, Yli-Pelkonen and Kohl 2005). The contribution of scientific evidence to policy implementation must thus be understood in relation to other knowledge forms, e.g. local knowledge (Geertz 2000, van Kerkhoff and Lebel 2006). Local knowledge is something acquired, possessed, and applied by local actors, relating e.g. to local biodiversity patterns, local institutions such as attitudes and customs, or local socio-ecological history. Local knowledge is thus related to local places, people, and organizations. Scientific knowledge and other knowledge forms as well as practical experiences intertwine at the local level when implementing voluntary conservation. Trade-offs may exist between different knowledge types, and stakeholder groups may have different perceptions of what connotes clear, relevant, reliable, and fair knowledge (Cash et al. 2003, Cook et al. 2013, Kangas et al. 2010, Sarkki et al. 2014). Institutional, social, cultural and individual factors also affect how science is implemented in practise (Klenk and Wyatt 2015).

In this paper, we study how understanding knowledge use during voluntary policy instrument implementation could increase the effectiveness of nature conservation. We study how different knowledges intertwine and interact in voluntary conservation by investigating the stakeholders' viewpoint on implementation practises and processes.

\section{Material and methods}

\subsection{Context of the voluntary conservation - Forest Biodiversity Programme}

The Forest Biodiversity Programme METSO (Government of Finland 2014, 2008) aims to halt biodiversity loss in southern Finland by involving private landowners, who own $60 \%$ of productive forestland in Finland (Finnish Official Statistics 2015). The Programme consists of several actions and aims to complement the sparse forest conservation network.

The Programme's main conservation mechanism involves forest owners offering land to be conserved as protection sites that are evaluated against ecological criteria. If accepted, the owners 
receive financial compensation for conserving the sites. In principle, private landowners can choose between permanent and fixed-term conservation, environmental subsidy agreements, and nature management projects. Often, however, only the permanent option is offered to them. Biodiversityoriented forest management and restoration on state-owned land are additionally encouraged in the Programme. The Programme has so far aided in the protection of nearly 50000 hectares (Koskela et al. 2015).

The Programme is planned to account for both people and nature (Paloniemi and Tikka 2008). Improving the knowledge base, extensive communication directed at landowners and collaboration has been included in the Programme's actions, alongside state subsidies (Government of Finland 2008). According to evaluations, the Programme has efficiently advanced biodiversity conservation; it has increased collaboration and trust between actors, and the implemented ecological criteria have succeeded in targeting conservation to habitats important for biodiversity and typical for the area (Laita et al. 2012). However, effectiveness of the Programme to protect forests has also been criticized, e.g. because of inadequate resources, the small size of the conserved sites and their limited connectivity (Laita et al. 2012).

\subsection{Focus group discussions}

We organized focus groups in May and November 2014, to invite stakeholders to discuss how the effectiveness of nature conservation policy could be increased by understanding knowledge use during voluntary forest protection implementation (Figure 1). Discussions were conducted in three Finnish locations: Southwest Finland (Rekijokilaakso, Somero), North-Karelia (Joensuu), and Pirkanmaa (Virrat). In structuring the discussions and to systematically explore the various aspects that the policy instrument values consist of we used Mickwitz (2003) policy evaluation criteria relevance, impact, effectiveness, persistence, flexibility, predictability, legitimacy, transparency and 
equity (Figure 1). To stimulate in-depth discussion and elicit different opinions we formulated localized statements designed to provoke debates on issues that the stakeholders encounter in their practical work (Appendix A). Approximately 12 statements based on six criteria were considered in each group (Appendix B). After presenting each statement, the discussion was guided by a facilitator who maintained an informal style, giving participants the freedom to also introduce other topics into the discussion.

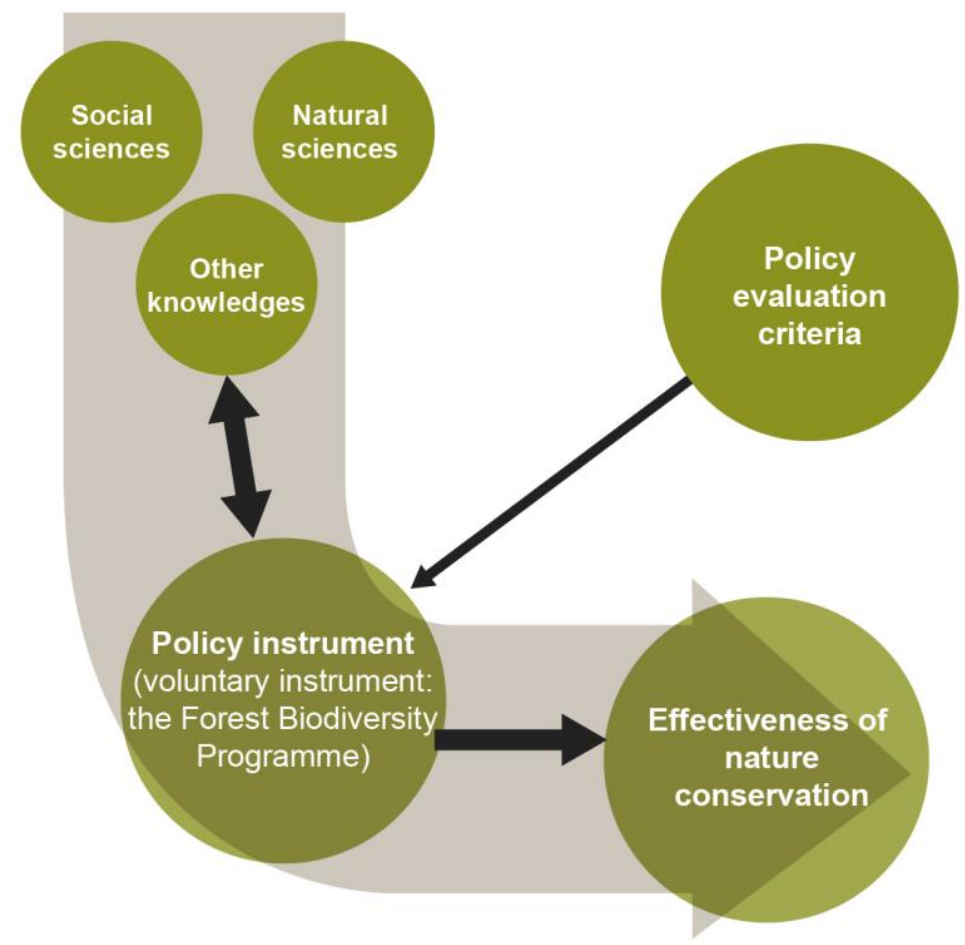

Figure 1. Our research design. We studied how the effectiveness of nature conservation policy could be increased (wide arrow). We assume that scientific knowledge and experiences of forest stakeholders intertwine when implementing voluntary conservation, and that effectiveness can be enhanced by understanding the phenomena linked to the use of sciences and other knowledge in implementation. Policy evaluation criteria were used to elicit opinions on various aspects that the policy instrument values consist of.

Focus groups (Krueger and Casey 2015) had four to eight participants each. Because researchpolicy linkages depend on transdisciplinary interaction, we aimed to involve versatile stakeholder 
groups with multifaceted forms of knowledge. Representations of various parties enabled a variety of different perspectives to emerge to complex problems and address relevant policy concerns (Carlsson et al. 2015). Specifically, we involved a total of 59 participants including scientists, forest advisers from Forest Management Associations (organizations administrated by forest owners, offering professional forest services), forest and environmental authorities, and landowners (Table 1). It should be noted that several participants had multiple roles. Participant selection was based on key informants' nominations of conservation and forestry actors in the study areas and on snowball sampling (Bazeley and Jackson 2013). The different stakeholder types were distributed evenly in the groups in each location. The discussions lasted approximately two hours each. The discussions were held in Finnish; excerpts and statements presented in this paper are translations. In the excerpts stakeholders are identified to the level of group theme, number, and organization (if possible to reveal while upholding anonymity).

Table 1. Focus group participants according to their main role. We organized three parallel groups at each location.

\begin{tabular}{llll}
\hline Stakeholder & Somero & Joensuu & Virrat \\
\hline Scientist & 3 & 3 & 3 \\
Landowner & 3 & 7 & 1 \\
Environmental authority (ELY-Centres for & 2 & 1 & \\
Economic Development, Transport and & & & \\
Environment) & & 4 & 2 \\
Forest administration (Forest Centre or & 3 &
\end{tabular}


organizations

The Central Union of Agricultural Producers 1

and Forest Owners

Regional Council

1

1

Tapio $^{1}$

2

Metsähallitus $^{2}$

1

1

Communications entrepreneur

Inventory performer/consultant

2

Total participants 59

${ }^{1}$ Tapio consulting services provide solutions for efficient and sustainable forest management and bioeconomy for both the public and private sectors. ${ }^{2}$ Metsähallitus administers the state forests; it runs business activities, but is also responsible for public services of protected areas.

\subsection{Analyses}

Discussions were transcribed verbatim. Data were analysed using an interpretative approach of qualitative content analysis (Berg 2001). The coding of the content was performed in NVivo software (Bazeley and Jackson 2013).

To study evidence use in the process of voluntary conservation, we first coded the data in three phases: (1) a broad categorization of knowledge-related topics (knowledge, research, and researchers), and (2) inductive subcategorization of these coded parts into themes. These themes revealed how evidence use was discussed. 
Subsequently, we looked closer at the above subcategories with an interpretative lens. We reflected on the relations between different subcategories, 3) which formed clusters of phenomena around implementation practises: i) applying locally bound knowledge, ii) awareness of voluntary conservation options, and iii) interaction and qualities of knowledges ${ }^{1}$. After founding these three categories, reflecting phenomena relevant to knowledge use, we summarize these categories and the relationships of the most important actors in a diagram. In the Results section, we open up these phenomena from the stakeholders' perspective. We analysed the content in relation to context, and also made interpretations from the dialogue process. We understand the discussions do not replicate, but reflect the actions taken by stakeholders in real-life situations (Bazeley and Jackson 2013).

\section{Results}

3.1. Knowledge use in the implementation of voluntary policy to protect forest biodiversity

According to the focus group discussions, forest owners and forest advisers are the key local-level actors in improving evidence-use and conservation contracting. Forest adviser's knowledge of the aims, means, and practises of biodiversity conservation matters in this process and is linked to her/his employer's organizational culture, potentially supporting both the adviser's and the owner's learning concerning conservation options and related ecological phenomena. The adviser's role is crucial in applying knowledge of biodiversity and helping the owner participate in the conservation endeavour. Forest owners and their knowledge are different, but we found the role of social context to be relevant: a positive relationship with other forest owners, forest advisers, and administration

\footnotetext{
${ }^{1}$ We also found a category of openness of knowledge, which however was related to other issues rather than voluntary conservation implementation, being more a technical discussion concerning the lack of access to databases and sector boundaries in forest management.
} 
can enhance the conservation decision. Positive relationships between all other actors were also said to increase the use of available knowledge. We also found that it is relevant for the knowledge used in voluntary conservation to be locally bound i.e. scientific knowledge is interpreted and applied in context of local knowledge, but also that the relevant actors must be aware of the voluntary instrument (Figure 2). We explain these in more detail in the following sections.

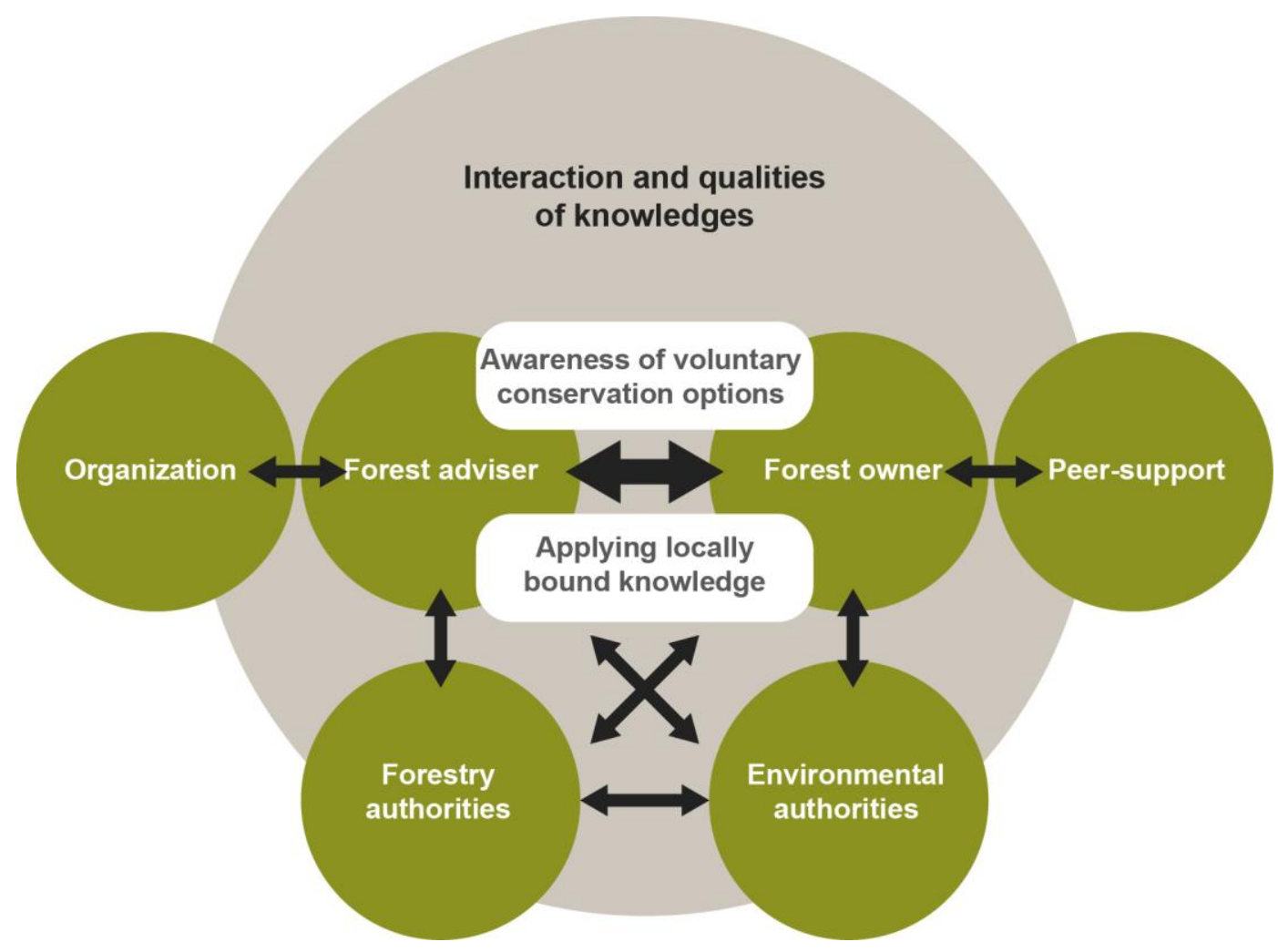

Figure 2. Forest advisers and forest owners are key actors affecting knowledge use in voluntary conservation implementation, and their collaboration can increase conservation effectiveness. The figure does not include all actors e.g. NGOs and scientists. Applying locally bound knowledge (i.e. scientific knowledge is interpreted and applied in context of local knowledge), awareness of conservation options, and the qualities and interaction of knowledges are important phenomena in conservation implementation.

3.2. Applying locally bound knowledge 
While discussing local-level policy implementation, participants gave examples of knowledge use, in which scientific knowledge was frequently applied or combined with local knowledge (both expert and lay) (Appendix C). For example, a forest adviser interprets whether a specific forest site matches with (conservation biology based and politically decided) conservation criteria and the forest owner is either aware or unaware that his/her forest is worth conserving:

"Maybe the case is that old forest owners know their forests, but we currently have so many distant forest owners, including me as well. And the next generations to come, they will be complete urbanites, and probably won't even know where their forest sites are located. In such a case I believe the knowledge is very limited or non-existent [laughs]." (Forest owner)

The discussions showed that in addition to forest advisers and owners, the authorities, NGO members, and other stakeholders have experience-based knowledge. Participants mentioned examples of knowledge gained while holding an expert position, such as forest adviser or authority that can be classified as expert knowledge, demonstrative examples being practical knowledge of procedures of establishing conservation area or experience-based, tacit knowledge on the location of sites listed in the Forest Act. Moreover, knowledge on local biodiversity and social customs in a locality were presented as relevant elements composing locally relevant expertise i.e. local knowledge.

From a local actor perspective, working behind the office desk far from forest localities was considered a negative aspect, and this was mentioned as a cause for not understanding local nature and the local environment:

"Well, I think, I got the impression that communication between local environmental authorities and the Ministry of the Environment doesn't work at all. Those in the Ministry make decisions basically without knowing anything of local issues. They just look at maps to draw boundaries where these appear suitable." (Forest owner) 
Stakeholders stated that educating forest advisers enhances bringing science-derived biodiversity knowledge into practise. For example, policy implementation guidelines are interpreted by practical actors. Accordingly, they called for more continuous education with practical field visits.

Stakeholders also acknowledged that developing the working responsibilities of forest actors may increase their knowledge requirements, like habitat and species identification skills, and updating knowledge for renewing responsibilities might require personal effort. Forest advisers' lack of selfconfidence concerning conservation requirements and procedures can prevent them from advising: if they do not know how to apply knowledge in a local context, they cannot advise.

Stakeholders reported that e.g. Forest Management Associations and the Forest Centre have arranged training, but such training does not currently focus on ecological phenomena. Stakeholders observed that forest advisers' knowledge is a combination of knowledge received from formal education, professional seminars, and their own local knowledge gathering based on personal experiences:

“-- we have received knowledge from researchers, and of course from textbooks and other sources. But we form our own conceptions from these.--“ (Forest Management Association)

Stakeholders expressed that environmental authorities often have more ecological knowledge than forest advisers. However, the authorities also argued that easier ways should exist for passing scientific information on to people at the local level:

“--I kind of wish it were somehow possible, but I don't know how these scientific results could end up here (--) at the grass-root level in the form of summaries or something like that, available to everybody who works with forests, or that a tool would be available through which they would arrive. Because I am lost, I have to admit it [laughing]. " (Environmental authority) 
Stakeholders expressed that in addition to a varying level of knowledge, forest owners and advisers have different values and attitudes towards conservation, remarkably affecting the ways that new policies and instruments are implemented in practise:

"There are people like X [name] who are broad-minded, but there are also, and let's say the majority of them [advisers] are those who don't even mention METSO [Programme], or conservation in general, or even environmental subsidies. I think that such information sharing does not even give forest owners the freedom of choice. "(Forest Centre)

The influence of individual forest advisers was said to be considerable, visible even on maps as concentrations of conserved areas in the territories of particular advisers. Contrastingly, explaining conservation was stated to be difficult in cases where advisers anticipate a negative attitude toward conservation from the forest owner. Moreover, it was mentioned that advisers also meet owners who are truly enthusiastic about conservation and know their own forest sites and ecological phenomena thoroughly. It was also noted that environmental authorities have personal attitudes. Attitudes within (forest) organizations concerning conservation and training and its costs were discussed to influence learning opportunities and possibilities to use working time for preparing conservation contracts. The goals and practises of the background organization were said to influence the advisers' possibilities regarding biodiversity-friendly advising:

"I would be quite cautious in blaming individual employees. I would first check whether they [forest advisers] really have, are they given, the chance to provide it [biodiversity friendly advising] -- “ (Forest scientist)

Explaining the justifications of conservation to landowners was considered important, partly because understanding the justifications was expected to increase participation in conservation. During the discussions, forest owners were often said to be interested in receiving knowledge regarding their land. Information concerning the amount of monetary compensation for 
conservation was said to be enough for some landowners, but both administration and Forest Centre officials mentioned that they do not restrict their information delivery to monetary compensation, but aim to also explain forest ecological patterns and processes to landowners. However, this communication was said and suggested to be done without utilizing scientific language, in a more practical way:

"'-- not once have I used [the concept of] 'metapopulation'. And not 'connectivity' either, not using that word. Of course I have said something like, when a conservation area is nearby, it's good to have more conserved areas [close by]. But not using those concepts. You should sense the knowledge level of the forest owner and their ability to receive information before you begin discussing anything very deep. Rather use terms like landscape, recreation, money. These are possibly of greatest interest to forest owners." (Forest Centre)

Discussions also highlighted that forest owners are more eager to listen to advisers' or authorities' explanations if they had worked with them in the past. The concepts used by scientists were considered difficult to understand and their use was associated with unwanted top-down communication. Stakeholders said that e.g. 'landscape conservation' was an understandable common-sense expression for many, however they said that the landowner might encounter different authorities that may use the same concepts for different issues, for example 'landscape'. Many natural phenomena are familiar to forest owners, but in different terms than those used in scientific discussions. However, it was mentioned that many landowners were not completely unfamiliar with scientific concepts, as they can be found e.g. in practical forestry newspapers. Some forest owners may thus arguably prefer more scientific reasoning.

Participants also discussed the role of scientists, who were considered and hoped to collaborate with practical actors to produce and share relevant information. Forest owners hoped for more information of studies concerning their own land, and scientists hoped for funding for disseminating results. Some scientists emphasized that interaction with practical actors is needed to produce 
relevant information. Scientists were seen as possible middle people between other stakeholders in policy processes, but mostly as information producers:

"I don't think scientists should be negotiation partners. Scientists produce information to people who negotiate-- “ (Central Union of Agricultural Producers and Forest Owners)

Local-level practitioners are thus key persons in interpreting knowledges in local context. Relationships and information sharing practises between all actors, including knowledge flows between administrative sectors, also affects the use of knowledge. Knowledge sharing can be enhanced in collaborative projects as mentioned, making databases and programmes compatible and ensuring the matching of database knowledge to local knowledge.

\subsection{Awareness of voluntary conservation options}

Forest owners' awareness of various voluntary conservation options, such as biodiversity-oriented forest management projects or permanent and fixed-term conservation, is necessary for implementing conservation policy. Discussions showed that forest owners can get information from general marketing, forest advisers, other forest owners, and other actors. Stakeholders expressed that interactions between landowners and other actors were crucial for raising awareness of conservation options. Forest advisers from Forest Management Associations have existing contacts and a trusted position among forest owners, because they traditionally give advice on forest management for timber production. Forest advisers can enhance the flow of biodiversity information as a part of their everyday work:

"I think that the easiest way for a forest expert to advise landowners concerning the Programme and biodiversity issues is to tell them concurrently as other forest management issues of the property are discussed, so that they become as by-product." (Anonymous stakeholder) 
Connections between forest advisers or forest owners and other actors were also considered important. One person representing an environmental authority explained how many various actors, such as forest companies, Forest Management Associations, and the Forest Centre are collaborating relating to the Programme, and can "deliver" suitable sites for conservation. In addition, many actors, including administration, scientists, forestry companies, and various non-governmental organizations were mentioned as providers of biodiversity conservation advice to forest owners.

Conservation advising alongside other work with landowners was mentioned to raise the background knowledge requirements among the actors:

"- The old-fashioned distribution of work, where everything happened fairly smoothly, has changed [laughing]. Nowadays everybody does everything, which is of course totally okay. In addition, it is good that a landowner has the freedom to obtain services from wherever s/he wants. However, this inevitably causes certain problems when everybody should also know everything." (Forest Centre)

Forest owners' collaboration with environmental authorities was considered to occasionally work very well. On the other hand, the authorities were also linked with unpleasant experiences concerning Natura 2000, producing potential challenges for implementation. Compared to Natura 2000, the Programme and wider information sharing were said to be reasons for improving relationships between environmental administrations and owners. The heavy workload of authorities was considered to occasionally restrict information sharing and marketing. In some cases, an environmental authority received enough offers for protection compared to the resources available (money for compensation and her/his own working time), and did not see the need for marketing.

Based on the discussions, knowledge of and interests towards conservation policies differ among forest owners; certain forest owners are more active than others in searching for information, they have different knowledge levels and varying aims. Forest owners' mutual collaboration can have a 
great impact on eventual conservation decisions. Reaching a high degree of conservation in NorthKarelia was explained with the advisers' and authorities' good relationships with the decisionmakers of voluntary conservation (i.e. forest owners) and the smooth collaboration between various actors (environmental authority, organizations, and companies). Working together in practical projects, which have also included non-governmental organizations as partners, was seen to have built trust among forest actors. Participating in the same practical conservation projects was even mentioned as a way of changing negative attitudes into more positive ones.

Positive experiences from other forest owners were said to be the best marketing tactic. Peer support was seen as especially important:

"I have highlighted this many times, it [conservation] begins with forest owners, and from neighbours and a forest owner's own village in particular. If there is an example in your village, they [conservation agreements] increase.--“ (Forest Management Association)

Acceptance of conservation was said to grow from the bottom up - stakeholders gave examples of single local individuals acting as initiators facilitating the management or conservation of wider continuous areas. Initiators of conservation may also come from outside the local community; forest owners may still not dare to openly show their interest in conservation:

"The reality is that an individual calls late in the evening, saying: "how was it with [conservation possibilities], could you organize it, I don't want to make a big issue of this". Acceptance in our village has grown slowly from the bottom up, and has led to the establishment of a conservation area.--" (Forest owner)

Discussed marketing actions included announcements in newspapers or contacting forest owners based on database information of valuable forests. All actions relating to the Programme, including successfully actualized conservation agreements, can be seen as marketing conservation. Still, opinions were shared that new forest owners may not be aware of the Programme. Stakeholders 
stated that specific projects have enabled more extensive information sharing than normal administrative work. Stakeholders explained that learning from previous experiences (particularly the implementation of Natura 2000) and the Internet as a new information channel have shaped information sharing:

"--there is public information sharing in the Programme, well, nowadays there are different channels for sharing information than there were when Natura was initiated. Many types of changes have occurred. Now there is probably more knowledge after those experiences [implementation of Natura 2000], but I don't have the perspective of an authority or other professional participating at that time" (Consultant)

The stakeholders hoped for more information sharing, e.g. they envisioned an information-sharing event in each village and information booklets that could be delivered to forest owners to inform them of valuable forests on valuable areas and of available conservation alternatives and management actions. It was also said that forest owners do not need to know beforehand the details of the contracting process, in many cases it is sufficient to only know whom to contact.

\subsection{Interaction and qualities of knowledges}

While discussing their experiences regarding the implementation of conservation policy, participants mentioned a wide variety of knowledge types, which we interpreted as originating in various scientific disciplines (including biology, forest sciences, and other natural sciences as well as social sciences and humanities) and being combinations of scientific and experience-based knowledge. Similarly, knowledge on nature was combined with knowledge on social and societal aspects such as neighbours' experiences on conservation or recent development of policy instruments and possibilities to implement the instruments in various localities. We found that in such integrative knowledge usage, scientific and collaboratively produced knowledge was applied 
(by interpreting for example the local impacts of climate change); that knowledge was often based on personal expertise and on understanding on local history and currently occurring processes, and that knowledge on 'biodiversity' was an outcome of interpreting and combining knowledge produced by for example natural scientist, local enthusiasts and private forest owners (Appendix C). Broad discussions related to ecology, forest sciences, and various biological knowledge types were not surprising. Participants stated that knowledge from social science disciplines is also important, because the Programme "aims to be a socially sustainable programme” (Anonymous stakeholder). The importance of changing practises based on both natural and social science knowledge was acknowledged:

"- the Programme has been directed in a way that enables natural and social science research findings to have an effect on practises. I think it is exceptional that it [the Programme] has been studied so much and that the funding [of research] also comes from the Programme.- . (Environmental authority)

Many of the mentioned scientific knowledge types were actually multi-, inter- or transdisciplinary such as biogeography and environmental policy. When talking of research, stakeholders seldom defined whether they referred to science or other types of research, e.g. referring to ecology as a science was obvious when a known researcher was mentioned by name or when ecologists discussed their own research.

The discussions showed that the question of what to conserve is a valuation question. Prioritizing different environmental protection targets was considered difficult. For example, the issue of which features to preserve (e.g. threatened species, amount of decaying wood, or structural characteristics of the forest) when conserving a forest area was mentioned multiple times. Finding a consensus concerning habitat types that require continuous management was even more difficult. Not all stakeholders accepted the same targets for conservation, e.g. discussion was held on connectivity 
versus isolated valuable areas. Even biodiversity conservation as the main target of the Programme was questioned, and some stakeholders suggested including social and cultural aspects as targets. Anyhow, many stakeholders emphasized the importance of ecology:

“--Nature is never similar, and its value can't be similarly monetized. We must make decisions based on nature values and not consider that everybody should get an equal share." (Forest owner)

"Well, if we simply consider which actions have the greatest ecological benefit for biodiversity conservation, it is ecology that should count. What we want to choose politically is another discussion, and these people selecting the conservation actions are chosen in elections.- “ (Anonymous stakeholder)

Social science knowledge and social values challenged the priority role of ecological knowledge in conservation decisions during the discussions. The social issues discussed included social sustainability, acceptance, freedom of choice, simplicity connected to time that advisers use when learning and explaining criteria, simplicity regarding monetary compensation, landscape aesthetics, recreation opportunities, traditions of owning land, and land owner's income. Discussions of fixedterm conservation showed how social and ecological knowledge can contest each other: ecological benefits, such as enabling natural succession, were primarily underlined in relation to permanent conservation, while many social benefits were mentioned in relation to temporary conservation such as leaving decision-making options to future generations.

Participants discussed several qualities of scientific knowledge, for example complexity compared to simplicity, legitimacy and uncertainty. Perceptions on complexity and clarity of the Programme's ecological criteria varied: views ranged from complicated enough to not detailed enough, and from difficult to "not rocket science" (biologist). The current payment scheme is based on loss of timber value caused by conservation (permanent private conservation area). Such a practise was criticized by some stakeholders as not reflecting nature values, while other stakeholders defended it as being a 
clear measure for most forest owners. This disagreement is illustrated in the following quotation, reflecting whether payment criteria should include only opportunity costs derived from market prices or also societally derived estimates for the ecological value (i.e. adding ecological knowledge to economics-driven justification):

"Are these nature values defined somewhere, what is a more valuable nature value and what is less valuable? In that case they should be defined, what is less valuable and how they are valued in money. Now when the value is counted based on timber value, it is at least a clear metric." (Forest owner)

It seems that qualities of science were mostly discussed with a hint of negativity. Reliability was often discussed indirectly through uncertainty. Sources of uncertainty in the mentioned ecological knowledge included uncertainty regarding what is sufficient conservation, not knowing all valuable areas, some data being collected by others than authorities, databases not being up to date, nature values changing drastically after logging, and scientific knowledge being continuously updated. According to stakeholders, inaccurate (species) data also increase distrust in the instruments and authorities. Some stakeholders saw preserving ecological connectivity and conserving larger areas as ways to decrease the risks of uncertainty. Climate change effects were discussed, but mostly seen as unpredictable and/or inevitable, and not as necessary aspects to take into consideration (apart from possibly conserving many sites). Uncertainty sources were also related to difficulties in predicting political, social, and natural changes in the future:

"Well, this is not easy [laughing]. What can actually be said to be permanent, if we think of the timescale of climate change i.e. decades, and if we then conserve abundant decayed wood, a coniferous forest or esker, there are changes all the time.--" (Forest scientist)

\section{Discussion}


Our study aimed to better understand the complexity of evidence use in policy implementation (Adams and Sandbrook 2013), to enhance the effectiveness of evidence-informed conservation. Our results suggest that the use of knowledge in conservation implementation can be enhanced. We found that knowledge has to be locally applicable to have an impact and that smooth social relationships enable integrating local knowledge with scientific knowledge. Interaction of various knowledges may have a complicating effect on knowledge use in practice. Awareness of conservation options and scientific reasoning behind them can be increased by educating forest advisers and supporting positive relationships between forest owners and other actors.

Importantly, as the present findings demonstrate, local knowledge is not disconnected from scientific knowledge. Giessen and Böcher (2009) approached the connection from the perspective of local knowledge and found that scientific knowledge has major role in the use, production and interpretation of local knowledge (see also van Kerkhoff and Lebel 2006). In the implementation of voluntary policy, local actors, such as forest advisers, affect (scientific) knowledge use by interpreting, sharing and co-producing it with other actors in a local context i.e. combining it with local knowledge. Spilsbury and Nasi (2006) have also recognized the site-specificity of natural resource management knowledge. Our results show that building information sharing channels, especially for forest advisers, and other knowledge mobilization actions may positively impact evidence use (see also Klenk and Wyatt 2015, Pullin and Knight 2003, Sutherland et al. 2004). However, the present results concerning the intertwined knowledge types indicate that emphasis should be placed not only on summarizing ecological research to practical actors, but also on incorporating knowledges from other disciplines and from the local level to the policy implementation process. Such knowledge integration may be operationalized e.g. through sciencepolicy interfaces and by means of formal relationships between research, decision-making, and mediating (boundary) organizations e.g. publicly funded research organizations, and training of 
forest professionals (Borie and Hulme 2015, Cash et al. 2003, Cook et al. 2013, Sarkki et al. 2014, Stevanov et al. 2013).

Raising awareness of conservation options is an important prerequisite for effective implementation in the case of a voluntary instrument. This is in line with Spilsbury and Nasi (2006), who list lack of awareness as one of the uptake constraints of research output. Our focus group discussants highlighted smooth social relationships as enabling factors in evidence use in voluntary policy (see also Cash et al. 2003, Oliver et al. 2014). For example, trusted forest advisers and fellow forest owners can advance the awareness of conservation options and individual's participation in conservation, which is also noted by earlier research (e.g. Korhonen et al. 2013). As well, Giessen and Böcher (2009) identified partnerships and regionalisation as important for policy implementation.

Furthermore, our results show that science-policy interface actors should be able to account for interaction and qualities of different types of knowledges, i.e., between knowledge from different disciplines and between scientific and experience-based knowledge. Knowledge mediators, e.g. advisers, may have an important role in how knowledges interplay in implementation; and also researchers have potential roles as integrators and policy entrepreneurs (Nagasaka et al. 2016). However, scientific institutions are not necessarily more influential redistributing knowledge than other knowledge dispersers Hasanagas (2016). How scientific knowledge is used during policy instrument implementation at the local level is affected by the valuation of different knowledges (Salomaa et al. 2016). Our observations are also in accordance with the results of Ellefson (2000), in that conflicting scientific conclusions and the disciplinary orientation of science hinders effective policy formulation. However, considering knowledge from social sciences and investing in knowledge sharing processes may have partly changed forest owners' attitudes to more positive towards conservation. 
Frameworks of policy processes should acknowledge differences between various policy instruments and be applicable also in the case of a voluntary policy instrument. For example qualities of science (e.g. clear, relevant, reliable, and fair, Cash et al. 2003, Cook et al. 2013, Sarkki et al. 2014) along with interaction of different knowledge types (Fortmann and Ballard 2011, van Kerkhoff and Lebel 2006, Yli-Pelkonen and Kohl 2005) have been discussed in the literature, but they have seldom been united to consider the effectiveness of policy implementation. Our present results give reason to assume that applying locally bound knowledge and fostering awareness of conservation options may be even more important when applying voluntary conservation instruments than command and control -type instruments. Perhaps that is the reason why these phenomena have not been highlighted in previous frameworks of policy processes. A need therefore exists to widen policy process frameworks and science-policy interface theories from science-policy links to links of science-policy-implementation.

In this study, we analysed knowledge use in a policy process leading to a "good" policy instrument, and in line, used policy assessment criteria (Mickwitz 2003), as a means to broaden the facilitated discussions of stakeholders. Through policy evaluation criteria, stakeholders were encouraged to consider the relevant types of knowledge in the conservation practises. Moreover, such a systematic approach strengthens the replicability of our research. The variety of stakeholders involved meant that issues were discussed from various angles. However, it is probable that many voluntary participants felt positive attitudes towards the Programme, although we also involved landowners with negative attitudes. Participants were co-operative in the discussions, whereas in reality individuals can sometimes have more contrasting perspectives.

During our study we did not try to separate in detail the different facilitating or barrier factors. We involved stakeholders in an attempt to increase practical relevance and additionally to improve the knowledge flow both ways between science and forest conservation practises. Science produced in collaboration with stakeholders may have a greater impact in practise (Fortmann and Ballard 2011), 
while local knowledge use increases policy acceptance (Giessen and Böcher 2009). Böcher (2016) has stressed that integration, the step between research and knowledge utilization in policy, works both ways. We argue that the involvement of stakeholders increases the understanding of possible solutions to complex problems, along with stakeholders' ownership and use of research findings, and thus needs to be combined with the evidence-based approach (Carlsson et al. 2015, Funtowicz and Ravetz 1993, Klenk and Wyatt 2015, Pullin and Knight 2003, Spilsbury and Nasi 2006, Sutherland et al. 2004). In this way a combination of policy instruments (Doremus 2003), which simultaneously increase evidence uptake, acceptance, and effectiveness of forest conservation, can be developed.

Our findings have noteworthy policy implications. For example, current human and monetary resources for biodiversity conservation will be even more limited in the near future, in Finland as well as in many other national contexts, encouraging us to pay even more attention to the effectiveness of voluntary conservation efforts. Policies should thus be designed in a way that allows the practical application of knowledge. In case of voluntary policy instruments, enough effort should be placed on awareness raising to ensure a sufficient supply for ecologically effective protection. Policymakers should understand the importance of different knowledge types. Use of scientific knowledge can be supported in different phases of the policy process, e.g. defining policy instruments in a way that allows their practical implementation (e.g. attractiveness to forest owners and clear guidelines for identifying habitats), educating forest advisers, informing stakeholders and particularly those making final decisions, such as land owners, on the existence of policy instruments. Policymakers should support collaboration (creating chances for learning and building trust) between forest actors.

Acknowledgements: We thank Annika Harlio, Maarit Jokinen, Sanna Kasurinen, Markus Nissinen, Eeva Primmer, Sari Pynnönen, Outi Ratamäki, and Sanna Tähtinen, ELY-centre Varsinais-Suomi, 
and Forest Centre North-Karelia for participating in data collection. We thank Per Mickwitz for discussing the use of policy evaluation criteria in our research design. We thank Stella Thompson for language editing and Erika Varkonyi for illustrations. We thank the Finnish Ministry for Agriculture and Forestry for funding our research project and the University of Helsinki Doctoral Programme in Interdisciplinary Environmental Sciences for the salary of AS.

\section{References}

Adams W.M. \& Sandbrook C. 2013. Conservation, evidence and policy. Oryx 47(3): 329-335. doi: $10.1017 / \mathrm{S} 0030605312001470$

Appelstrand M. 2002. Participation and societal values: the challenge for lawmakers and policy practioners. Forest Policy and Economics 4: 281-290. http://dx.doi.org/10.1016/s13899341(02)00070-9

Bazeley P. \& Jackson K. 2013. Qualitative data analysis with NVivo. Sage Publications, London. $328 \mathrm{p}$.

Berg B. 2001. Qualitative research methods for the social sciences. Allyn and Bacon, Boston. 304p.

Borie M. \& Hulme M. 2015. Framing global biodiversity: IPBES between mother earth and ecosystem services. Environmental Science \& Policy 54: 487-496.

http://dx.doi.org/10.1016/j.envsci.2015.05.009

Böcher M. 2016. How does science-based policy advice matter in policy making? The RIU model as a framework for analyzing and explaining processes of scientific knowledge transfer. Forest Policy and Economics 68: 65-72. 
Böcher M. \& Krott M. 2014. The RIU model as an analytical framework for scientific knowledge transfer: the case of the "decision support system forest and climate change". Biodiversity and Conservation 23(14): 3641-3656. http://dx.doi.org/10.1007/s10531-014-0820-5

Carlsson J., Eriksson L.O., Öhman K. \& Nordström E.-M. 2015. Combining scientific and stakeholder knowledge in future scenario development - A forest landscape case study in northern Sweden. Forest Policy and Economics 61: 122-134. http://dx.doi.org/10.1016/j.forpol.2015.08.008 Cash D., Clark W., Alcock F., Dickson N., Eckley N., Guston D. \& Mitchell R. 2003. Knowledge systems for sustainable development. PNAS 100(14): 8086-8091. doi:10.1073/pnas.1231332100 Cook C.N., Mascia M.B., Schwartz M.W., Possingham H.P. \& Fuller R.A. 2013. Achieving conservation science that bridges the knowledge-action boundary. Conservation Biology 27(4): 669-678. http://dx.doi.org/10.1111/cobi.12050

Doremus H. 2003. A policy portfolio approach to biodiversity protection on private lands. Environmental Science and Policy 6: 217-232. http://dx.doi.org/10.1016/s1462-9011(03)00036-4 Ellefson P.V. 2000. Integrating science and policy development: case of the national research council and US national policy focused on non-federal forests. Forest Policy and Economics 1: 8194. http://dx.doi.org/10.1016/s1389-9341(99)00006-4

Finnish Official Statistics 2015. Ownership of forest land. Natural Resources Institute Finland, Helsinki. http://stat.luke.fi/en/ownership-forest-land (Accessed 15.6.2016)

Fortmann L. \& Ballard H. 2011. Sciences, Knowledge and the Practice of Forestry. Eur J Forest Res 130: 467-477. doi:10.1007/s10342-009-0334-y

Funtowicz S. \& Ravetz J.R. 1993. Science for the Post-Normal Age. Futures 25: 735-755. http://dx.doi.org/10.1016/0016-3287(93)90022-1

Geertz C. 2000. Local knowledge: further essays in interpretive anthropology. Basic Books, USA. 
Giessen L. and Böcher M. 2009. Rural Governance, forestry, and the promotion of local knowledge: The case of the German rural development programme 'Active Regions'. Small Scale Forestry 8 (2): 211-230.

Government of Finland 2008. Finnish Government Resolution on the Forest Biodiversity Programme for Southern Finland 2008-2016 (METSO). 27.3.2008 [in Finnish] http://www.metsonpolku.fi/download/noname/\%7BA51BCBD0-0CAB-47B9-8F3BC7482A8DDFF4\%7D/115128 (Accessed 21.6.2016)

Government of Finland 2014. Finnish Government Resolution on the continuation of Forest Biodiversity Programme for Southern Finland 2014-2025. 5.6.2014 [in Finnish] http://www.ym.fi/download/noname/\%7BE4BA4C28-3815-4E62-87B5AF9226CF749C\%7D/100323 (Accessed 21.6.2016)

Hasanagas N.D. 2016. Managing information in forest policy networks: Distinguishing the influential actors from the "postmen”. Forest Policy and Economics 68: 73-80.

Hiedanpää J. 2002. European-wide conservation versus local well-being: the reception of the Natura 2000 Reserve Network in Karvia, SW-Finland. Landscape and Urban Planning 61:113-123.

Janse G. 2006. Information search behaviour of European forest policy decision-makers. Forest Policy and Economics 8(6): 579-592. http://dx.doi.org/10.1016/j.forpol.2004.10.001

Janse G. 2008. Communication between forest scientists and forest policy-makers in Europe - A survey on both sides of the science/policy interface. Forest Policy and Economics 10(3): 183-194. http://dx.doi.org/10.1016/j.forpol.2007.10.001

Jenkins W. 1978. Policy analysis: A Political and Organizational Perspective. Martin Robertson, London. 278p. 
Jordan A., Wurzel R., Zito A. \& Brückner L. 2003. European Governance and the Transfer of 'New' Environmental Policy Instruments (NEPIs) in the European Union. Public Administration 81(3): 555-574. http://dx.doi.org/10.1111/1467-9299.00361

Kangas A., Saarinen N., Saarikoski H., Leskinen L.A., Hujala T. \& Tikkanen J. 2010. Stakeholder perspectives about proper participation for Regional Forest Programmes in Finland. Forest Policy and Economics 12(3): 213-222. http://dx.doi.org/10.1016/j.forpol.2009.10.006

Klenk N. L. \& Wyatt S. 2015. The design and management of multi-stakeholder research networks to maximize knowledge mobilization and innovation opportunities in the forest sector. Forest Policy and Economics 61: 77-86. http://dx.doi.org/10.1016/j.forpol.2015.06.008

Korhonen K., Hujala T. \& Kurttila M. 2013. Diffusion of voluntary protection among family forest owners: decision process and success factors. Forest Policy and Economics 26: 82-90. http://dx.doi.org/10.1016/j.forpol.2012.08.010

Koskela T., Anttila S., Syrjänen K. \& Kuusela S. 2015. METSOn tilannekatsaus 2014. Luonnonvara- ja biotalouden tutkimus 28. [in Finnish] http://jukuri.luke.fi/handle/10024/485986 (Accessed 21.6.2016)

Krueger R.A. \& Casey M.A. 2015. Focus groups. A practical guide for applied research. Sage Publications, Thousand Oaks. 252p.

Laita A., Horne P., Kniivilä M., Komonen A., Kotiaho J., Lahtinen M., Mönkkönen M. \& Rämö A.-K. 2012. METSO-ohjelman väliarvio 2012. [in Finnish] http://www.metsonpolku.fi/download/noname/\%7B9C59F8AD-1C03-4C94-8E2919E910D71447\%7D/116640 (Accessed 16.6.2016)

Mickwitz P. 2003. A Framework for Evaluating Environmental Policy Instruments: Context and Key Concepts. Evaluation 9(4): 415-436. http://dx.doi.org/10.1177/1356389003094004 
Nagasaka K., Böcher M. \& Krott M. 2016. Are forest researchers only scientists? Case studies on the roles of researchers in Japanese and Swedish forest policy processes. Forest Policy and Economics 70: 147-154.

Oliver K., Innvar S., Lorenc T., Woodman J. \& Thomas J. 2014. A systematic review of barriers to and facilitators of the use of evidence by policymakers. BMC Health Services Research 14: 2. http://dx.doi.org/10.1186/1472-6963-14-2

Paloniemi R. \& Tikka P. 2008. Ecological and social aspects of biodiversity conservation on private lands. Environmental Science \& Policy 11(3): 336-346.

http://dx.doi.org/10.1016/j.envsci.2007.11.001

Primmer E., Paloniemi R. et al. 2014. An approach to analysing scale-sensitivity and scaleeffectiveness of governance in biodiversity conservation. In: Padt F., Opdam P. et al. (eds.) Scalesensitive governance of the environment. John Wiley \& Sons, Oxford. pp. 241-262.

Pullin A.S. \& Knight T.M. 2003. Support for decision making in conservation practice: an evidence-based approach. Journal for Nature Conservation 11(3): 83-90. http://dx.doi.org/10.1078/1617-1381-00040

Salomaa A., Paloniemi R., Kotiaho J.S. Kettunen M., Apostolopoulou E. \& Cent J. 2016. Can green infrastructure help to conserve biodiversity? Environment and Planning C: Government and Policy. In press. doi: 10.1177/0263774X16649363

Sarkki S., Niemelä J., Tinch R., van den Hove S., Watt A. \& Young J. 2014. Balancing credibility, relevance and legitimacy: A critical assessment of trade-offs in science-policy interfaces. Science and Public Policy 41(2): 194-206. http://dx.doi.org/10.1093/scipol/sct046 
Spilsbury M.J. \& Nasi R. 2006. The interface of policy research and the policy development process: challenges posed to the forestry community. Forest Policy and Economics 8: 193- 205. http://dx.doi.org/10.1016/j.forpol.2004.09.001

Stevanov M., Böcher M., Krott M., Krajter S., Vuletic D. \& Orlovic S. 2013. The Research, Integration and Utilization (RIU) model as an analytical framework for the professionalization of departmental research organizations: Case studies of publicly funded forest research institutes in Serbia and Croatia. Forest Policy and Economics 37: 20-28.

Sutherland W.J., Pullin A.S., Dolman P.M. \& Knight T.M. 2004. The need for evidence-based conservation. Trends in Ecology and Evolution 19(6): 305-308. http://dx.doi.org/10.1016/s01695347(04)00073-4

van Kerkhoff L. \& Lebel L. 2006. Linking Knowledge and Action for Sustainable Development. Annual Review of Environment and Resources 31(1): 445-477. http://dx.doi.org/10.17226/11652 Yli-Pelkonen V. \& Kohl J. 2005. The Role of Local Ecological Knowledge in Sustainable Urban Planning: Perspectives from Finland. Sustainability: Science, Practice, \& Policy 1(1).

Appendix A. Statements used in the focus groups in Southwest Finland (Rekijokilaakso, Somero). Statement phrasing was slightly modified for the subsequent focus group events in North-Karelia (Joensuu), and Pirkanmaa (Virrat), based on local biodiversity conservation profiles (see Appendix B) and learning gained during the research process. However, the basic meaning behind each statement remained the same. We used Mickwitz's (2003) criteria for environmental policy evaluation as the viewpoints providing structure to the interview guide. Of these we used general criteria (relevance, impact, effectiveness, persistence, flexibility, predictability) and democracyrelated criteria (legitimacy, transparency, equity). We considered the democracy-related criteria important in the present case, because the Finnish Biodiversity Programme METSO was initiated in the aftermath of social conflicts caused by the top-down implementation of the Natura 2000 programme.

\begin{tabular}{ll}
\hline Criteria & $\begin{array}{l}\text { Statements used in the focus groups to } \\
\text { stimulate discussion }\end{array}$ \\
\hline 1. Relevance & $\begin{array}{l}\text { Biodiversity conservation through management } \\
\text { is the most important environmental target in }\end{array}$ \\
$\begin{array}{l}\text { Do the goals of the instruments cover key } \\
\text { environmental problems? }\end{array}$ & \begin{tabular}{l} 
Rekijokilaakso. \\
\hline
\end{tabular}
\end{tabular}


[The Forest Biodiversity Programme] METSO programme brings additional value to the conservation of traditional biotopes in Rekijokilaakso.

Persons who implement METSO should regularly meet with scientists and they should negotiate the targets together.

2. Impact

Is it possible to identify impacts that are clearly due to the policy instruments and their implementation?
METSO has also had other impacts than biodiversity conservation, e.g. the acceptance of nature conservation has increased.

The METSO programme has improved or disrupted social relationships among different actors in the area.

Management of traditional rural biotopes advances forest owner satisfaction with biodiversity conservation.

\section{Effectiveness \\ To what degree do the achieved outcomes correspond to the intended goals of the policy instrument?}
Altering the management actions of economically utilized forests can yield more positive effects on forest species than increasing conservation areas.

Forest owners should try to find solutions together for protecting biodiversity at the landscape level.

The forest management association [forest owners' service and lobby organization] is closer to landowners than nature conservation authorities are, and therefore negotiates more smoothly with landowners.

The proportion of fixed-term contracts should be decreased for the benefit of permanent conservation agreements.

Biodiversity-oriented forest management projects improve the network of conserved areas if they are situated near national parks or other valuable conserved areas.

[Biodiversity-oriented] Forest operations that are performed only once can cause permanent improvement. 


5. Flexibility
Can the policy instrument cope with changing
conditions?
conditions?
Forests could be cut in an agreed manner prior to the permanent conservation of an area to save costs.

When prioritizing METSO conservation areas, one should consider how nature features could be conserved in a changing climate.

Fixed-period conservation agreements are better than permanent agreements because they enable including new targets in nature conservation programmes in the future.
When planning the METSO programme, the amount of required knowledge, advice and resources provided were evaluated better than during the Natura 2000 programme.

Future actions can be planned in a way that conserves biodiversity based on current knowledge.

\section{Legitimacy \\ To what degree do individuals and organizations, such as non-governmental organizations, interest organizations and firms, accept the environmental policy instrument?}

Forest-based livelihoods should be considered already during the preparation of land-use planning to combine different objectives.

Other actors besides landowners perceive METSO as fair and legitimate.

An initiative from forest owners is essential for the acceptance of cross-border conservation planning.

\section{Concepts relevant to conservation, such as} "metapopulation" and "connectivity", should be better explained in biodiversity advising.

Knowledge of valuable sites on private land belongs to all citizens, and thus information concerning, e.g. the existence of flying squirrel, should be openly accessible if it does not threaten the protection of the species.

Making a METSO conservation agreement or a biodiversity-oriented forest management agreement is easy, and rationales for compensation are easy to understand. 
How are the outcomes and costs of the environmental policy instrument distributed? Do all participants have equal opportunities to take part in and influence the processes used by the administration? programme [ecological prioritization software], to direct the marketing of conservation opportunities to the owners of valuable sites.

Authorities should make conservation contracts with all landowners using the same eligibility and compensation rules despite differing nature values.

Landowners' and nature enthusiasts' knowledge does not impact the selection of METSO conservation areas strongly enough. 
Appendix B. Statements addressing six out of nine policy evaluation criteria were discussed in each group at three locations (see Appendix A, criteria numbers in boxes). The discussion theme was locally relevant for each location; landscape in Southwest Finland (landscape-level advisory processes and traditional rural biotopes), biodiversity-oriented forest management in North-Karelia (new Forest Act, herb-rich forests and their management), and old-growth forests in Pirkanmaa. The first three criteria in each group were considered using three statements (with one exception: criteria 6 was considered using only two statements in the Southwest Finland group 3) and the following three criteria with one statement. The purpose of this interviewing design was to ensure a wide and balanced yield of stakeholders' views within and across the three locations without making the individual discussions too long and taxing for participants.
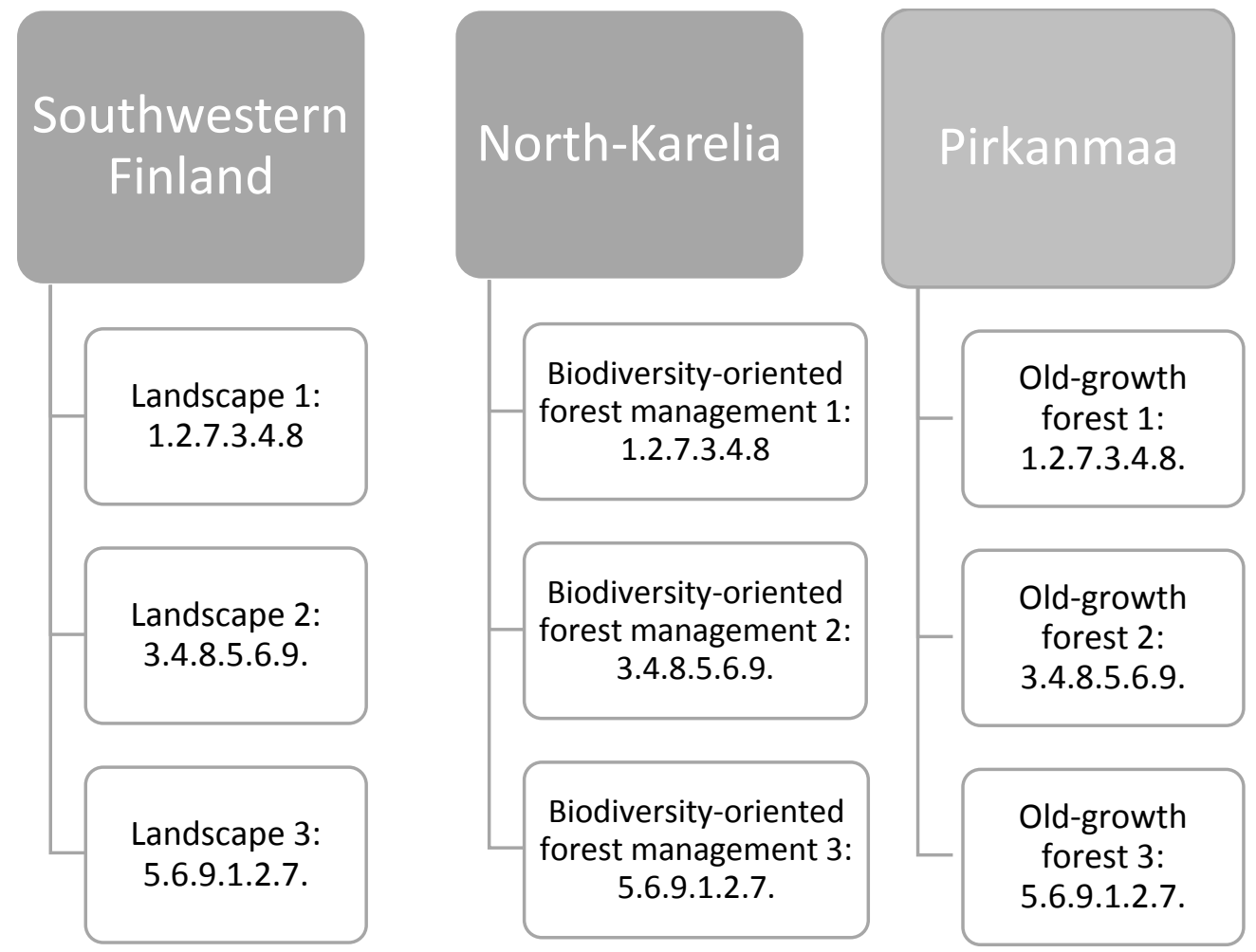
Appendix C. Examples of various knowledge types mentioned in the discussions, which we interpreted as originating from different disciplines and constituting varying combinations of scientific and experience-based knowledge.

\begin{tabular}{ll}
\hline Examples of knowledge types mentioned & Scientific disciplines \\
\hline ecological knowledge & Biology \\
conservation biology & \\
species dispersal & \\
knowledge on natural succession & \\
habitat types & \\
connectivity & \\
metapopulation dynamics & \\
forest economics research & Forest sciences \\
harvesting survey & \\
influence of continuous growth on timber quality & \\
knowledge of pest risk & \\
research on forest's ability to capture carbon & \\
natural science research & Natural sciences (excluding the \\
knowledge on changing climate & abovementioned) \\
biogeography & \\
long time series & Social sciences \\
social sciences knowledge & \\
policy studies & \\
laws & \\
cost efficiency & \\
environmental policy research & \\
research on attitudes & \\
research of forest owners \\
knowledge on conservation willingness \\
cultural knowledge
\end{tabular} $\begin{aligned} & \text { knowledge of landscape } \\
& \text { knowledge of landscape history } \\
& \text { landscape management }\end{aligned}$

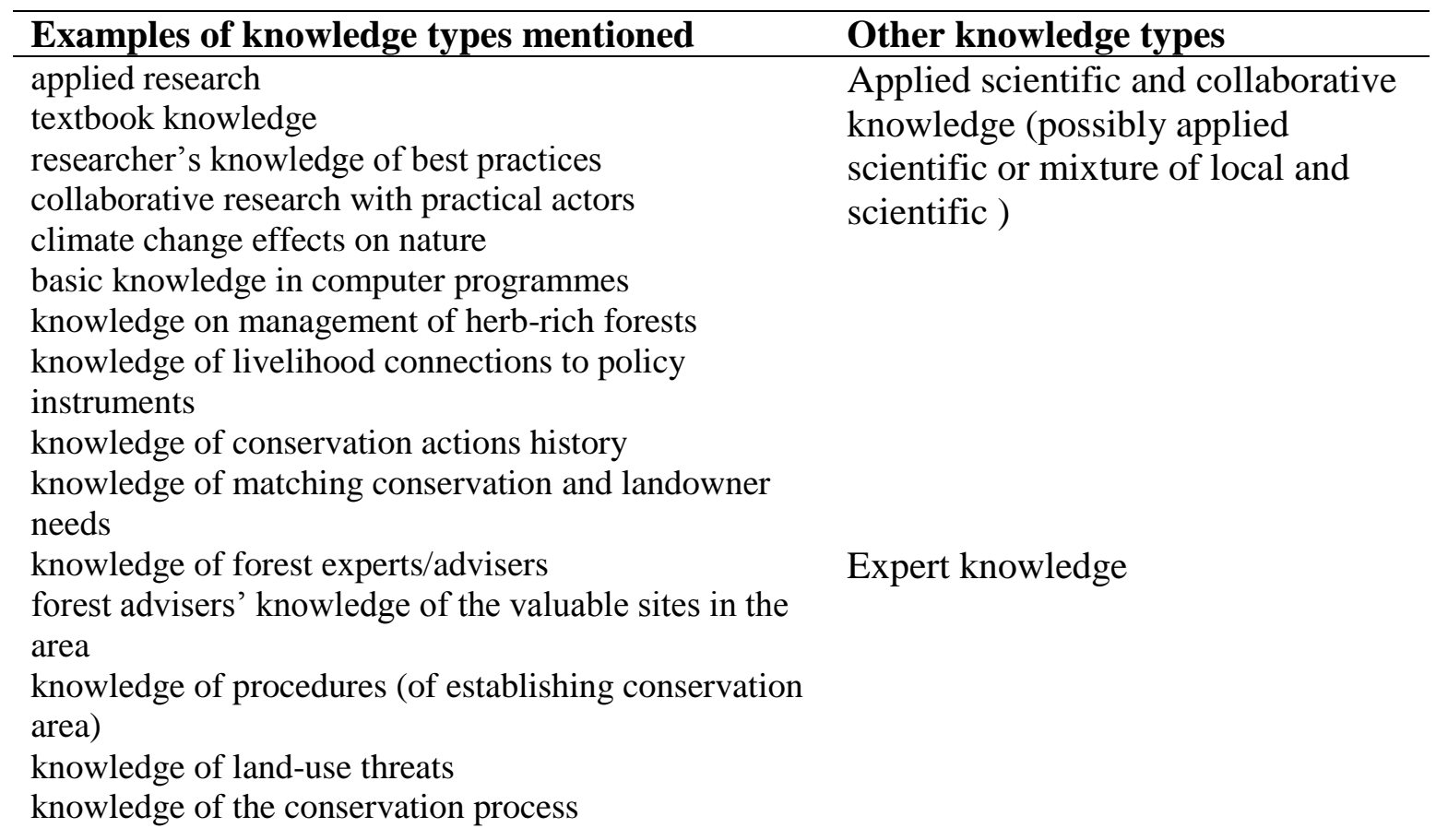


knowledge on the location of sites listed in the Forest

Act

knowledge concerning region

inherited knowledge/traditions

knowledge of local issues

knowledge of neighbour's actions

grass root-level knowledge

nature enthusiasts' knowledge

knowledge on targeting conservation

knowledge concerning species

knowledge of site succession

knowledge of vulnerable species

knowledge of lekking sites of birds and nesting trees

forest owner's knowledge of valuable sites in the area
Local knowledge

Biodiversity knowledge (possibly applied scientific or mixture of local and scientific)) 